\title{
DESCARTE DE MÁSCARAS NAS IMEDIAÇÕES DE EQUIPAMENTOS DE SAÚDE PÚBLICA NA PANDEMIA DO COVID-19 EM ARAGUAÍNA-TO
}

\author{
M. C. SILVA \\ Universidade Federal do Tocantins \\ ORCID ID: https://orcid.org/0000-0001-9062-3954 \\ marivaldoareia@yahoo.com.br
}

Submetido 17/05/2020 - Aceito 17/11/2020

DOI: $10.15628 /$ holos.2020.10136

\section{RESUMO}

O uso de máscaras no cotidiano dos brasileiros basicamente, se remete a obrigatoriedade para alguns profissionais que tem a exigência do uso enquanto equipamento de proteção individual (EPI) e em profissionais de saúde que tem como obrigatoriedade o uso. O objetivo do texto tem como meta central observar o descarte de máscaras nas imediações do HRA, da UPA e UBS, do setor Araguaína Sul, no período da Pandemia do covid-19, na cidade de Araguaína-TO antes do decreto municipal da obrigatoriedade do uso por toda a população. $O$ estudo trata de uma pesquisa qualitativa de natureza exploratória com observações e uso de registros fotográficos. Foram adotadas medidas de prevenção de distanciamento social e segurança para evitar contato com as máscaras descartadas. Observou-se um número significativo de máscaras jogadas nas imediações da área pesquisada. Profissionais de vários segmentos, incluindo da saúde, que descartaram máscaras ao sair do HRA, UPA e UBS. Outros materiais descartados de modo indevido como toucas e luvas brancas de uso hospitalar, são encontrados facilmente nas imediações da área estudada

PALAVRAS-CHAVE: Máscaras; pandemia; Covid19; Araguaína-TO.

\section{DISPOSAL OF MASKS IN THE VICINITY OF PUBLIC HEALTH EQUIPMENT REGARDING THE COVID-19 PANDEMIC IN ARAGUAÍNA-TO}

\begin{abstract}
The use of masks in the daily life of Brazilians basically refers to the obligation for some professionals who have the requirement to use it as personal protective equipment (PPE), and for health professionals, who have the obligation to use it. The main objective of the text is to observe the disposal of masks in the vicinity of HRA, UPA and UBS in the Araguaína Sul sector during the Pandemic 19 period in the city of Araguaína-TO, before the municipal decree of mandatory use throughout the population. The study deals with a qualitative research
\end{abstract}

of exploratory nature with observations, and use of photographic records. Measures to prevent social distance and safety were adopted to avoid contact with discarded masks. There was a significant number of masks thrown in the vicinity of the researched area. Professionals from various segments, including health, who discarded masks when leaving HRA, UPA and UBS. Other materials improperly discarded, such as burrows and white gloves for hospital use, are easily found in the vicinity of the studied area

KEYWORDS: Masks; pandemic; Covid-19; Araguaína-TO.

HOLOS, Ano 36, v.5, e10136, 2020 


\section{INTRODUÇÃO}

Com origem em Wuham, na província de Hubei região central da China, o avanço do novo coronavírus ${ }^{1}$, denominado SARS-CoV-2, sobre os países tem gerado a interrupção das atividades cotidianas da população, devido à necessidade de isolamento social para frear o avanço da doença, que em menos de 4 meses já expandiu para 190 países, incluindo o Brasil (WHO, 2019a). Os principais sinais e sintomas, constatados inicialmente, provocados pelo vírus incluem febre, tosse e dificuldade para respirar (BRASIL, 2019b). Sintomas gastrointestinais, como diarreia, vômitos e dor abdominal também foram relatados para o coronavírus disease (COVID-19), assim como nas infecções por outros coronavírus.

A transmissão da doença costuma ocorrer pelo ar ou pelo contato direto das pessoas e se dá principalmente, por meio de gotículas de saliva, espirro, tosse e secreções que podem contaminar mãos e superfícies (BRASIL, 2019a; LOPES e SILVA, 2020). Em estudos de revisão, foram confirmados vários sintomas como a febre, tosse, cansaço, anosmia (perda do olfato) hiposmia (diminuição do olfato) agenia (perda do sentido do paladar), sintomas gastrointestinais, dor abdominal, diarréia, vômito, náusea, dores de cabeça, tontura, faringalgia, mialgia e anorexia também foram diagnosticados e identificados como sintomas da COVID-19 em alguns pacientes (WANG et al. 2020).

Como medidas para tentar frear a propagação do vírus, a Organização Mundial da Saúde (OMS) e as principais autarquias de saúde no Brasil divulgaram como cuidados: higienizar as mãos, cobrir a boca com o antebraço ou lenço descartável ao tossir e espirrar, evitar aglomerações e manter-se em isolamento domiciliar, por até 14 dias, em caso de sintomas da doença (WHOa, 2019). Também é incentivada a manutenção das pessoas em ambientes bem ventilados e que as empresas e instituições públicas considerem a realização de trabalho remoto (home office), reuniões virtuais, adiamentos e cancelamentos de viagens também são indispensáveis (WHOa, 2019)

Inicialmente, a Organização Mundial da Saúde e a Organização Pan-Americana da Saúde (OMS/OPAS/BRASIL, 2019) recomendaram uso de máscaras basicamente para profissionais de saúde e portadores de sintomas respiratórios, como tosse ou dificuldade de respirar, inclusive, ao procurar atendimento médico profissionais de saúde e pessoas que prestam atendimento a indivíduos com sintomas respiratórios. Com isso, não seria necessário o uso de máscaras para pessoas que não apresentem sintomas respiratórios. Houve também a preocupação com a quantidade de máscaras disponíveis em todo o mundo enquanto equipamento de proteção individual (EPI). No entanto, atenta para o uso de máscaras em alguns países de acordo com os hábitos culturais locais.

\footnotetext{
${ }^{1}$ Compreende por “Coronavírus é uma família de vírus que causam infecções respiratórias. Alguns coronavírus podem causar doenças graves com impacto importante em termos de saúde pública, como a Síndrome Respiratória Aguda Grave (SARS), identificada em 2002, e a Síndrome Respiratória do Oriente Médio (MERS), identificada em 2012. O novo agente do coronavírus (SARS-CoV-2) foi descoberto no final de 2019 após casos registrados na China e provoca a doença chamada de Covid-19". http://www.ans.gov.br/aans/noticias-ans/consumidor/5344-coronavirus-confira-informacoese-saiba-como-se-prevenir. Acessado em: 21/03/20.
} 
Em função do avanço, da gravidade, da alta letalidade e da capacidade de atuação do sistema de saúde em vários países que a covid-19 vem demonstrando grande avanço, a OMS, líderes mundiais, com algumas exceções, e várias autoridades de saúde mundiais passaram a indicar a obrigatoriedade do uso de máscaras em locais públicos através de decretos. No Brasil, o Ministério da Saúde (MS) também passou a recomendar o uso de máscaras, inclusive de fabricação caseira, como foi o caso da cidade de Araguaína-TO, através do decreto $217 / 20^{2}$.

É possível que fatores culturais, aliados ao desconhecimento quanto da importância do uso correto das máscaras, para conter a disseminação do COVID-19, induza ao descarte indevido por parte da população, dentre eles, servidores da área da saúde. Foi comprovado a eficácia das máscaras mediante uso adequado, aliado a demais práticas como distanciamento social, uso de álcool gel, lavagem constante das mãos com água e sabão.

O presente artigo é parte de estudos preliminares sobre a temática e tem como meta central observar o descarte de máscaras nas imediações do Hospital Regional de Araguaína (HRA), da Unidade de Pronto Atendimento (UPA) e Unidade Básica de Saúde (UBS) do setor Araguaína Sul no período da Pandemia do COVID-19 na cidade de Araguaína-TO, antes do decreto municipal da obrigatoriedade do uso por toda a população.

\section{METODOLOGIA}

Araguaína é um município do estado do Tocantins, região norte do Brasil. Segundo o IBGE(2010) possui população de 150.484 e estimativa populacional para 2019 de $180.470^{3}$, possui área de 4.000,416 km², 37,62 hab/km², latitudes 7ㅇ 11' 28” sul e longitude 48 12 '26” a oeste, divisa com as cidades de Babaçulândia, Nova Olinda, Piraquê, Santa Fé do Araguaia e Wanderlândia, como mostra a figura 1.

Figura 01 - Mapa de localização de Araguaína no Tocantins.

\footnotetext{
${ }^{2}$ Araguaína é a primeira cidade brasileira a obrigar moradores a usarem máscaras respiratórias em locais públicos. A regra começa a valer a partir do dia 17 de abril e foi regulamentada pelo Decreto Municipal no 217/20, que está publicado no Diário Oficial dessa segunda-feira, 6 de abril de 2020.

${ }^{3}$ https://cidades.ibge.gov.br/brasil/to/araguaina/panorama. Acesso em 20/04/2020.
}

HOLOS, Ano 36, v.5, e10136, 2020 


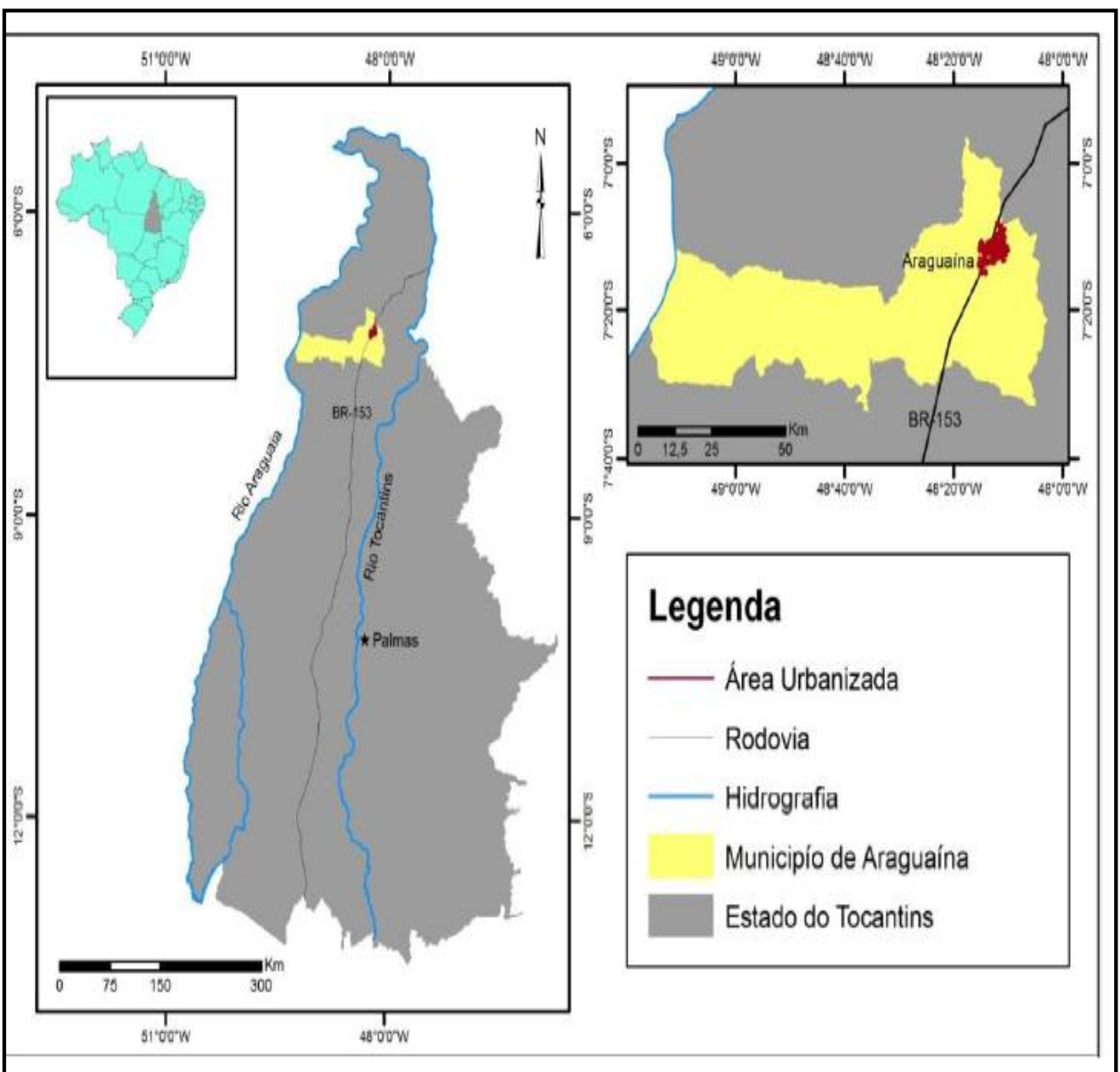

Fonte. A. A. Nascimento, 2017

O estudo, deste trabalho, é de natureza qualitativa, com observação em campo. Como amostra, foi escolhido as imediações do Hospital Regional de Araguaína (HRA) no centro da cidade, a Unidade de Pronto Atendimento (UPA) e a Unidade Básica de Saúde (UBS), ambas localizada no setor Araguaína Sul, todos públicos com atendimento pelo Sistema Único de Saúde (SUS).

Quanto a pesquisa qualitativa, Minayo (2001) afirma que:

A pesquisa qualitativa responde a questões muito particulares. Ela se preocupa, nas ciências sociais, com um nível de realidade que não pode ser quantificado. Ou seja, ela trabalha com o universo de significados, motivos, aspirações, crenças, valores e atitudes, o que corresponde a um espaço mais profundo das relações, dos processos e dos fenômenos que não podem ser reduzidos à operacionalização de variáveis. (MINAYO, 2001, pg. 21-22)

Entendemos dessa maneira, que as formas de descartes de máscaras, em áreas inadequada, se enquadram perfeitamente como objeto de estudo qualitativo, a partir da observação. No texto original de Jean Poupart, Jean-Pierre Deslauriers Lionei-H. Groulx Anne Laperriere Robert Mayer e demais autores, cuja obra denominada de La recherche qualitative - grifos nossos - traduzido por 
Ana Cristina Nasser em 2008, discorre sobre a observação na pesquisa qualitativa, enfoques epistemológicos e metodológicos.

No texto os autores chamam a atenção para a observação clandestina onde afirma que:

A observação clandestina é também escolhida no caso de situações sociais complexas ou de meios quase inacessíveis sem essa dissimulação. Nesta circunstância, é uma lógica de acessibilidade que orienta a estratégia. Por exemplo, Claster e Schwartz (1972) citam algumas pesquisas nas quais a identidade dos pesquisadores não foi revelada para que eles pudessem, no fim das contas, realizar um estudo que não teria podido ocorrer diferentemente. Este é o caso principalmente dos estudos sobre as instituições totais (o hospital psiquiátrico, a prisão, o exército), ou sobre grupos fechados, tais como as gangues ou as seitas. (POUPART, et. al. 2008. pg. 14).

O deslocamento da residência para as observações ocorreu em veículo próprio evitando aproximação social. Diante do universo de pesquisa, os registros fotográficos, identificado o descarte, ocorreram na medida do possível sem pedestres próximos por medida de segurança. Nas proximidades do Hospital Regional de Araguaína, os registros fotográficos foram realizados após as 21h. Tanto na UPA, quanto na UBS, as observações e registros foram realizados próximo ao meio dia.

Os registros fotográficos foram realizados usando o Smartphone Motorola One XT1941, preto, 64GB, tela de 5,9", dual chip, android 8.1, câmera traseira dupla, processador Octa-Core e 4GB de RAM. Na formatação das fotografias, não se adotou o preenchimento. Foi utilizado cor sólida preta, com largura de 1,75pt. Para destacar as máscaras e demais materiais descartados observados foi inserido círculo vermelho também com 1,75pt.

A pesquisa seguiu as recomendações de distanciamento social recomendado pela OMS, OPAS e do MS que recomendam manter distância mínima de 2 metros entre as pessoas.

Outras medidas foram utilizadas como meio de proteção, a saber: lavagem das mãos com água e sabão, uso de álcool gel, álcool 70, máscara de proteção que, antes de serem descartadas, foram imersas em hipoclorito de sódio numa proporção de $10 \mathrm{ml}$ para um litro de água. Após 30 minutos foram retiradas e colocadas em lixeira fechada para coleta do lixo domiciliar.

O desenvolvimento do estudo quanto ao descarte correto das máscaras teve embasamento nos protocolos da Agência Nacional de Vigilância Sanitária (ANVISA). Houve a revisão teórica da NOTA TÉCNICA № 47/2020/SEI/GIALI/GGFIS/DIRE4/ANVISA, que trata do uso de luvas e máscaras em estabelecimentos da área de alimentos no contexto do enfrentamento ao COVID-19. Essa revisão visou atualizar a Nota Técnica no 15/2020/SEI/GGALI/DIRE2/ANVISA e a Nota Técnica no 18/2020/SEI/GGALI/DIRE2/ANVISA, que trata especificamente da relação às recomendações do sobre o uso de máscara (ANVISA, 2020).

De modo a complementar o estudo, apesar de ser um ponto de vista técnico, mas de importância para o contexto do estudo, foi realizado por meio remoto via WhatsApp, diálogo com uma médica que trabalha no HRA e HDT para esclarecimentos sobre o uso e descarte de máscaras. 
Na oportunidade foi abordado o uso e descartes de máscaras caseiras na pandemia do COVID-19 em Araguaína Tocantins.

\section{RESULTADOS E DISCUSSÃO}

Nas imediações do HRA (figura 02) foi suficiente percorrer poucos metros, na Rua Ademar Vicente Ferreira, para encontrar diversas máscaras descartadas de modo irregular nas calçadas e, também, em meio ao asfalto. Localizada na área central da cidade, durante o dia geralmente e verificado uma alta concentração e circulação de pedestres, alto fluxo de circulação de motocicletas, e veículos nas imediações do HRA. Também são áreas que possuem nas proximidades reservas para taxistas e mototaxistas, além de embarque e desembarque de pacientes, acompanhantes, viaturas policiais, veículos destinados ao uso hospitalar como ambulâncias, viaturas do Serviço de Atendimento Móvel de Urgência (SAMU) que transportam pacientes de Araguaína e região.

Cabe fazer uma associação aos resíduos sólidos de saúde (RSS). Estes foram divididos em grupos a partir da Resolução 05/93 do Conselho Nacional do Meio Ambiente (CONAMA, 1993). Em 05 de março de 2003, a ANVISA define na RDC 33/03 que os RSS passariam a ser classificados em cinco grupos separados. De qualquer maneira, em relação ao descarte de máscaras usadas por profissionais de saúde, a literatura trata como lixo hospitalar. No caso da população de Araguaína, o uso de máscaras ganha expressão na pandemia do COVID-19. Porém, algumas situações são necessárias destacar, como a forma de uso, tempo de uso, tipo de máscara, capacidade de segurança e descarte dessas máscaras. 
Figura 2 - Máscaras descartadas na Rua Ademar Vicente Ferreira ao lado do Hospital Regional de Araguaína-TO

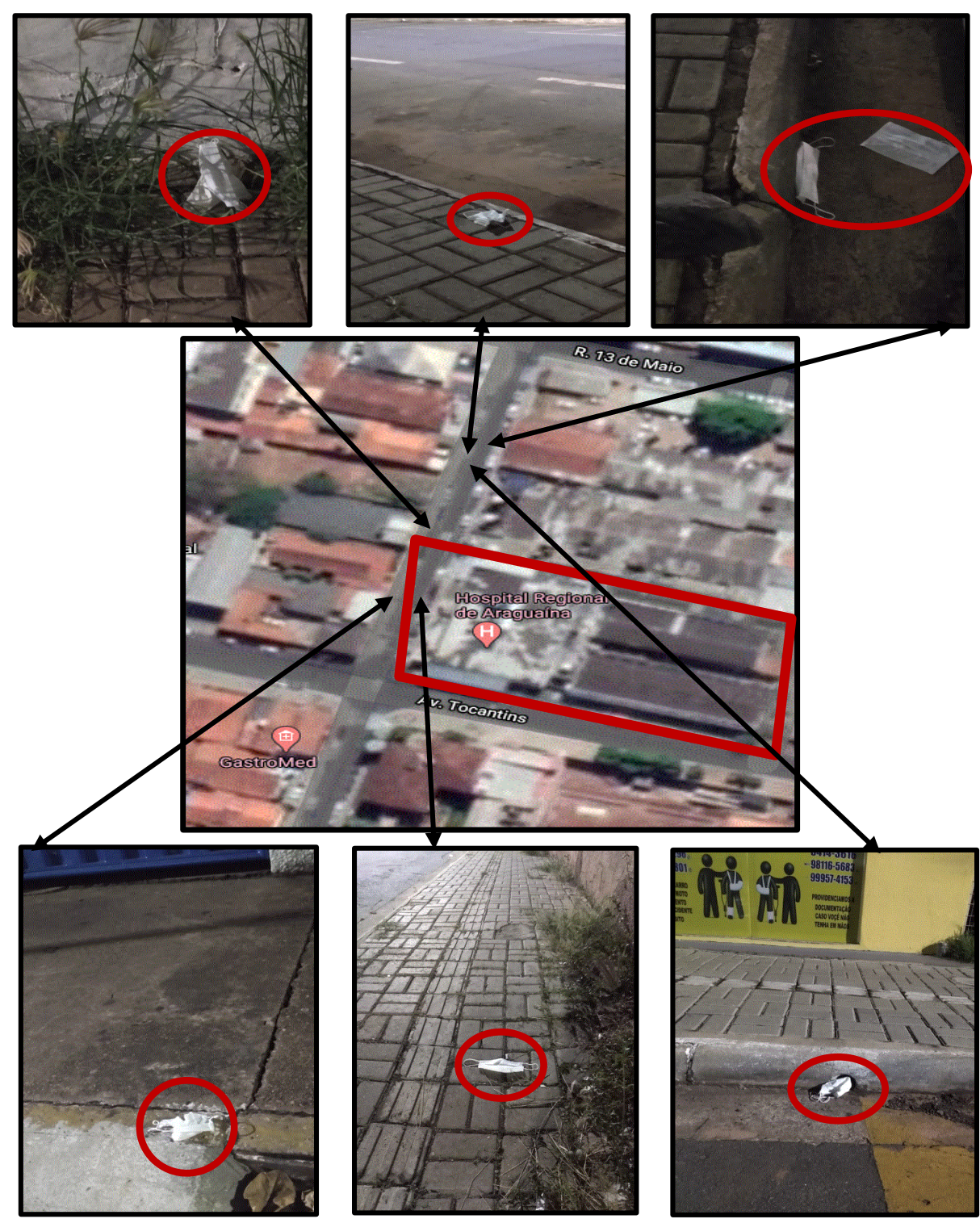

Fonte: SILVA, M. C. 05/04/2020

Foi publicado no dia 8 de setembro no The New England Journal of Medicine ${ }^{4}$, que é um jornal científico, um estudo intitulado "Facial Masking for Covid-19 - Potential for Variolation as We Await a Vaccine" , onde aponta que o uso de máscara facial tem o poder de gerar uma resposta imunológica no corpo humano contra a infecção pelo novo coronavírus.

Monica Gandhi e Rutherford(2020) afirmam que:

[...] might help reduce the severity of disease and ensure that a greater proportion of new infections are asymptomatic. If this hypothesis is borne out, universal masking could become a form of

${ }^{4}$ https://www.nejm.org/doi/full/10.1056/NEJMp2026913.

HOLOS, Ano 36, v.5, e10136, 2020 
"variolation" that would generate immunity and thereby slow the spread of the virus in the United States and elsewhere, as we await a vaccine. (GANDHI; RUTHERFORD, 2020. pg. 1).

No resultado da pesquisa desenvolvida, os autores comprovaram que o mascaramento universal, minimiza a carga viral da população para sintomáticos e assintomáticos. Há uma relação entre os países asiáticos que tiveram uso em massa de máscaras pela população e o controle da pandemia do SARS de 2003. Quando se reduz a carga viral inalada, é possível que a infecção ocorra de maneira leve e subsequente imunidade sem doenças graves e menos mortes.

Vários são os motivos para validar a importância da pesquisa sobre o descarte inadequado das máscaras em locais público como pode ser verificado na figura 3.

Figura 3 - Máscaras descartadas nas imediações da UPA/UBS no setor Araguaína Sul na cidade de Araguaína-TO

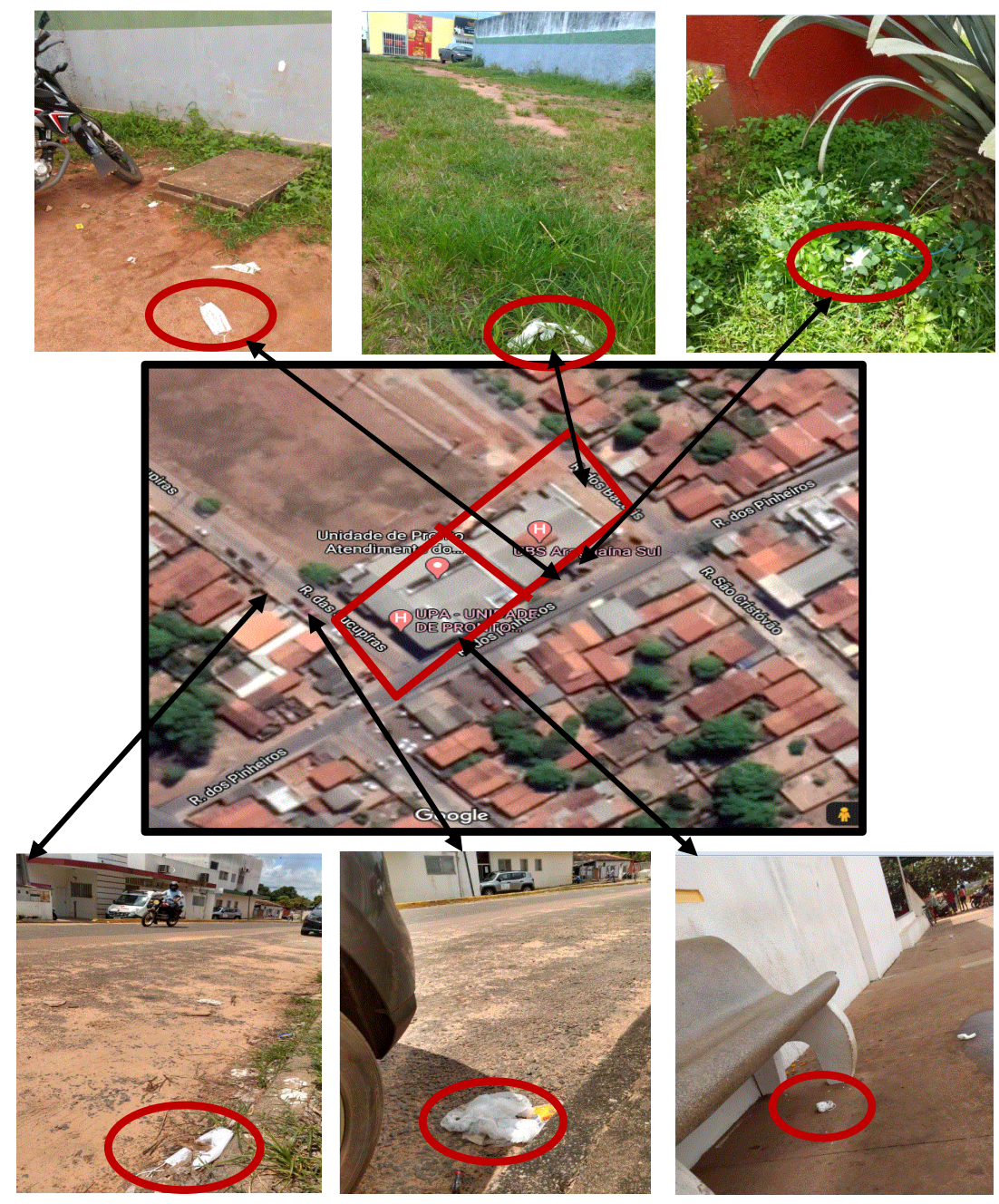

Fonte: SILVA, M. C.. 05/04/2020

No caso do Brasil, além de não ser prática corriqueira o uso das máscaras pela população, - salvo em casos de profissionais de áreas específicas - como em alguns países asiáticos, existem outros fatores que 
corroboram para o não uso e o descarte incorreto das máscaras. Por exemplo, parte dos apoiadores do atual presidente da república, Jair Messias Bolsonaro, que se apresenta com comportamento negacionista quando se trata do tema em pauta, podendo induzir a disseminação do vírus em larga escala como apontaram (LOPES e SILVA, 2020).

Importante ressaltar que os resíduos gerados nos estados sólidos ou semi-sólido, são definidos como produto resultante de atividades da comunidade, seja de origem industrial, doméstico (resíduo comum), hospitalar, comercial, pública, agrícola, de serviços, varrição, entre outros, são normatizados conforme a NBR 10004 da Associação Brasileira de Normas Técnicas (ABNT, 1987).

Os registros fotográficos que remetem a parte superior da figura 3, são do descarte de máscaras e luvas brancas de uso hospitalar próximos a UBS. Foi encontrado e fotografado máscaras na porta central de entrada da unidade de saúde. As observações comprovaram que os descartes não ocorreram apenas por pacientes e visitantes do local. Parte dos profissionais da saúde descartam esse tipo de material hospitalar com naturalidade.

Para Maria de Jesus (nome fictício) médica que trabalha no HRA e no Hospital de Doenças Tropicais (HDT) da cidade de Araguaína-TO, uma máscara só pode ser lavada 4 vezes e depois jogada fora. Quanto ao procedimento de lavagem das máscaras caseiras de modo adequado, ela afirma ser necessária deixá-la de molho por 40 minutos em água com $10 \mathrm{ml}$ de $\mathbf{Q b o a ^ { 5 }}$, secar no sol quente e passá-la com ferro quente antes de usar novamente.

Próximo à entrada da UPA, embaixo do banco de cimento havia mascara descartada, nas calçadas na frente, ou paralela também existiam várias, assim como nas ruas e a céu aberto. Outros materiais descartados são as toucas brancas e esparadrapos. Essas toucas e luvas, principalmente, são considerados materiais de equipamento de proteção individual que devem ser descartados de modo que proporcione segurança para o usuário e demais segmentos sociais. Também para evitar contaminação do ar, da água e do solo por exemplo.

Takayanagui (2005) esclarece que os resíduos, quando são manejados de modo indevido, representam riscos ao meio ambiente pela possibilidade de poluir o solo, os lençóis de água subterrâneos e o ar em função da sua decomposição. Quanto a saúde humana, pelos riscos de contaminação indireta ou direta por possuírem características propícias à sobrevivência e proliferação de alguns animais, que podem se tornar focos de reservatórios de agentes causadores de doenças. As máscaras, além do supracitado, passam a fazer parte de uma "paisagem comum", "natural" na cidade.

Estudos internacionais realizados no período da quarentena na China e em Cingapura, recém-publicados na revista científica Lancet Gastroenterol Hepatol, mostraram que os pacientes da doença tinham em suas fezes, o material genético do vírus, mesmo depois de não apresentar mais no pulmão, ou nas vias respiratórias (CRUZ, 2020).

\footnotetext{
${ }^{5}$ Expressão bastante utilizada no Tocantins e outras regiões do Brasil. É uma marca de Água sanitária.
} 
Segundo o autor, a primeira pesquisa analisou amostras de fezes e do trato respiratório de 98 pacientes e foi realizada no Hospital Universitário de Sun Yat-sen, em Zhuhai, na China, entre 16 de janeiro e 15 de março, durante o período da ocorrência da Covid-19.

Outra implicação importante para destacar no texto é sobre a situação sanitária brasileira como aponta Cruz, vejamos:

[...] considerando a situação sanitária do Brasil, em que apenas $46 \%$ do esgoto gerado no país são tratados (segundo o Sistema Nacional de Informações sobre Saneamento - SNIS 2018), é que nos meses em que durar a pandemia poderemos estar despejando em nossos rios uma enorme carga viral. (CRUZ, 2020, pg. 1-2)

Outro estudo realizado na Holanda, detectou o novo coronavírus em amostras de esgotos do aeroporto de Schiphol, em Amsterdã, bem como em Estações de Tratamento de Esgoto (ETE) das cidades de Kaatsheuvel e Tilburg (esta última trata o esgoto do aeroporto de Schiphol), após duas semanas da confirmação do primeiro paciente com COVID-19, a doença causada pelo novo coronavírus, na região. Esses estudos indicam que os esgotos podem contribuir para a proliferação da COVID-19 e no caso de Araguaína, com os descartes das máscaras a céu aberto, pode ocorrer situação similar.

Portanto, o estímulo e obrigatoriedade do uso de máscaras, por uma gama de pessoas que não tem a preocupação devida e adequada com o descarte das mesmas, poderá contribuir com o aumento e disseminação do vírus Sars-CoV-2 no ambiente. Proporcionar a infecção da população mais vulnerável. Outro risco, recai no contato direto por parte de crianças ou coletores e catadores de lixo pois, não há um isolamento rigoroso na cidade de Araguaína.

Também é importante destacar a possibilidade de poluição e contaminação de corpos hídricos, uma vez que esse material pode ser facilmente transportado para os bueiros e bocas de lobo e, posteriormente, chegarão nos córregos, rios e represas ocasionando danos socioambientais. Dependendo do tipo de material que a máscara é confeccionada, seja algodão, poliéster, ou fibras sintéticas, poderá demorar entre um ano ou centenas para se decompor.

Sendo assim, o desenvolvimento, a venda e o incentivo a distribuição de máscaras biodegradáveis seriam uma boa alternativa, desde que não comprometesse a saúde humana. Mesmo assim, cabe ressaltar, que esse tipo de material deveria ser destinado como coleta seletiva para evitar propagação de doenças.

\section{CONSIDERAÇÕES FINAIS}

O estudo através das observações, revelou grande quantidade de máscaras descartadas por pessoas de vários segmentos sociais. Em determinadas situações, nas proximidades das áreas de saúde estudadas, também foram observados profissionais de saúde fazendo o descarte de máscaras em calçadas e lotes baldios. Sendo assim, como sugestão, a partir das observações e constatações, 
é pertinente que os cursos da área de saúde apresentem melhores abordagens para o uso e descarte de máscaras que além de ser um EPI é, também, considerado lixo hospitalar que carece de descarte em local apropriado.

Novos estudos devem ser realizados e, que estes, possam contribuir para disseminação do conhecimento e formas adequadas de descartes das máscaras. Com o decreto municipal 217/20 que trata da obrigatoriedade do uso de máscaras por toda população de Araguaína em locais públicos, é possível que haja maior possibilidade de riscos à saúde em função do descarte inadequado das máscaras. Sem as devidas informações, teremos uma maior quantidade de máscaras descartadas a céu aberto em meio a ruas, praças, calçadas, lotes baldios e demais vias públicas.

Torna-se fundamental adotar medidas que possam reduzir os riscos. Difundir por meios de revistas científicas, mídias diversas, com maior abrangência possível, seja por meios de canais de tvs, jornais escritos, carros de som circulando nas ruas da cidade, programas de rádio, entre outros meios de alcance populacional, haja vista que estamos em período de isolamento social parcial em função da pandemia da COVID-19.

Fica evidente, que o uso de máscaras em situações dessa natureza, não faz parte da rotina e da cultura da população residente na área estudada. Nem tão pouco o processo correto de descarte das mesmas. A higienização das mãos deve ser corriqueira para evitar contágio. Temos uma compra pressurosa do álcool em gel para fins de higienização, mas, essa prática deveria ser diária pois evitaria a transmissão de doenças infecciosas através das mãos. O descarte das máscaras ocorreu por usuários ou acompanhantes de pacientes que estavam a pé, em motocicletas, de dentro dos veículos, imediatamente após a saída das áreas de saúde observadas.

Recomenda-se o descarte conforme orientações e sugestões propostas pela ANVISA. Independentemente se a máscara foi confeccionada de tecido, TNT, seja ela de uso profissional, como determina o Ministério da Saúde que recomenda máscaras cirúrgicas e N95/PFF2 priorizadas para os profissionais das áreas de saúde.

\section{REFERENCIAIS}

ABNT. (1987). Associação Brasileira de Normas Técnicas, NBR -10004: Resíduos sólidos classificação. Rio de Janeiro.

ANS. AGÊNCIA NACIONAL DE SAÚDE SUPLEMENTAR. (2020). Coronavírus (COVID-19): confira informações e saiba como se prevenir. http://www.ans.gov.br/aans/noticiasans/consumidor/5344-coronavirus-confira-informacoes-e-saiba-como-se-prevenir (acesso em 21/Mar/2020).

BRASIL. Agência Nacional de Vigilância Sanitária.(2020). ORIENTAÇÕES GERAIS - Máscaras faciais de uso não profissional Brasília, 03 de abril de 2020a. Disponível em: 
http://portal.anvisa.gov.br/documents/219201/4340788/NT+M\%C3\%A1scaras.pdf/bf430184-8550-

42cb-a975-1d5e1c5a10f7. Acessado em: 03/10/2020.

BRASIL. AGÊNCIA NACIONAL DE VIGILÂNCIA SANITÁRIA. (2020). O novo coronavírus pode ser transmitido por alimentos? Brasília, 03 de junho de 2020b. Disponível em:

http://portal.anvisa.gov.br/noticias/-/asset publisher/FXrpx9qY7FbU/content/o-novo-coronaviruspode-ser-transmitido-por-alimentos-/219201. Acessado em 03/10/2020.

CRUZ, E. da S. de V. (2020). Coronavírus: esgoto pode ser via de contágio, indicam estudos. BBC NEWS BRASIL. 02/04/2020 https://www.bbc.com/portuguese/brasil-52143119. Acessado em: $20 / 04 / 2020$

IBGE. INSTITUTO BRASILEIRO DE GEOGRAFIA E ESTATÍSTICA. (2020). https://cidades.ibge.gov.br/brasil/to/araguaina/panorama. Acesso em: 21/04/2020

LOPES, A. P; SILVA, M. C. (2020). A Cidade de Araguaína-To na Rota do Convid-19: Reflexões Geográficas da Invisibilidade de um Vírus. Rev. FSA, Teresina, v.17, n. 9, art. 6, p. 112-134, set. 2020 MINAYO, Maria Cecília de Souza (org.). (2001). Pesquisa Social. Teoria, método e criatividade. 18 ed. Petrópolis: Vozes, 2001.

Monica Gandhi, M.D., M.P.H.; George W. Rutherford, M.D. (2020). Facial Masking for Covid-19 Potential for "Variolation. The New England Journal of Medicine. Disponível em: https://www.nejm.org/doi/full/10.1056/NEJMp2026913. Acessado em: 04/10/2020

Poupart, J. Et. Al. (2008). La recherche qualitative. A Pesquisa Qualitativa: Enfoques epistemológicos e metodológicos. Tradução de Ana Cristina Nasser. Petropolis, RJ: Vozes, 2008. (Coleção Sociologia). https://edisciplinas.usp.br/pluginfile.php/1932953/mod resource/content/1 LCELLARD\%2C\%20Andr\%C3\%A9 An\%C3\%A1lise\%20documental.pdf. acesso em 17/04/2020.

Takayanagui, A. Magoso. (2005). Gerenciamento de Resíduos de Serviços de Saúde. In: Philippi Jr. Arlindo. Editor. Saneamento, saúde e ambiente: fundamentos para um desenvolvimento sustentável. Barueri, SP: Manole. (Coleção Ambiental)

Wang, Z.; Yang, B.; Li, Q.; Wen, L.; Zhang, R. (2019). Clinical Features of 69 Cases With Coronavirus Disease 2019 in Wuhan, China, Clinical Infectious Diseases, Volume 71, Issue 15, 1 de agosto de 2020, Pages 769-777, https://doi.org/10.1093/cid/ciaa272. Acessado: 28/09/2020.

WHO. World Health Organization. Coronavirus disease (COVID-19) pandemic. 2019a. https://www.who.int/emergencies/diseases/novel-coronavirus-2019 (acessado em 20/Mar/2020).

WHO. World Health Organization. (2019). Coronavirus disease (COVID-19) advice for the public 2019b.https://www.who.int/emergencies/diseases/novel-coronavirus-2019/advice-forpublic (acesso em 21/Mar/2020). 
OPAS/OMS/BRASIL. (2020). Folha informativa - COVID-19 (doença causada pelo novo coronavírus).https://www.paho.org/bra/index.php?option=com content\&view=article\&id=6101:c ovid19\&Itemid=875. Acessado em: 09/04/2020.

\section{COMO CITAR ESTE ARTIGO:}

Silva, M. C. (2020). Descarte de máscaras nas imediações de equipamentos de saúde pública na pandemia do Covid-19 em Araguaína-TO. Holos. 36(5), 1-13.

\section{SOBRE OS AUTORES}

\section{C. SILVA}

Dr. em Geografia pela Universidade Federal de Uberlândia com trabalho na área de geografia da saúde abordando Leishmaniose Visceral. Mestre em Geografia pela Universidade Federal da Paraíba (UFPB). Licenciado pela Universidade Estadual da Paraíba (UEPB). Prof. Dr. do curso de Geografia em Araguaína-TO UFT. Prof. no Programa de Pós-Graduação em Estudos de Cultura e Território. Atua nas áreas relacionadas com a sociedade, natureza e o desenvolvimento, Degradação ambiental, uso e gestão dos recursos hídricos e geografia da saúde. E-mail: marivaldoareia@yahoo.com.br

ORCID ID: https://orcid.org/0000-0001-9062-3954

Editor(a) Responsável: Francinaide de Lima Silva Nascimento Pareceristas Ad Hoc: JOÃO CABRAL E LEANDRO COSTA

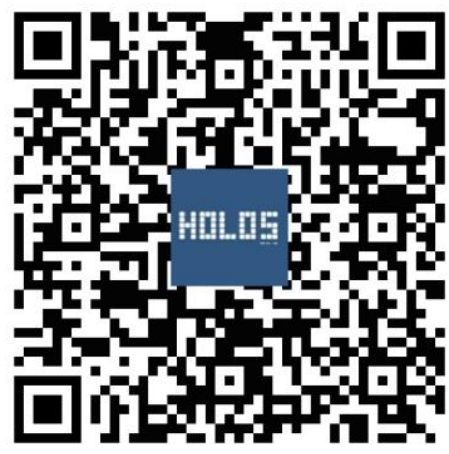

